\title{
Compósito de Resina de Poliéster Insaturado com Bagaço de Cana-de-Açúcar: Influência do Tratamento das Fibras nas Propriedades
}

\author{
Elisabete M. S. Sanchez, Claudia S. Cavani, Claudinete V. Leal, Caio G. Sanchez \\ Faculdade de Engenharia Mecânica, UNICAMP
}

\begin{abstract}
Resumo: Neste trabalho foi avaliada a influência do tratamento de fibras de bagaço de cana-de-açúcar nas propriedades mecânicas e dinâmico-mecânicas, na estabilidade térmica, na densidade e absorção de água, quando utilizadas na preparação de compósitos com resinas de poliéster insaturado em comparação com a resina sem reforço. As fibras foram submetidas a tratamento químico com solução alcalina de hidróxido de sódio. O tratamento melhorou as propriedades de impacto, aumentou o módulo de elasticidade em flexão, não alterou significativamente o módulo de elasticidade em tração dos compósitos em relação à resina sem reforço e melhorou a compatibilidade fibra matriz quando comparada com compósitos com a fibra sem tratamento, o que pode ser observado nas fraturas de impacto analisadas por microscopia eletrônica de varredura. As superfícies das fibras também foram avaliadas por microscopia eletrônica de varredura.
\end{abstract}

Palavras-chave: Resina de poliéster insaturado, bagaço de cana-de-açúcar, mercerização, propriedades mecânicas, propriedades dinâmico-mecânicas, adesão fibra-matriz.

\section{Unsaturated Polyester Resin Composite with Sugar Cane Bagasse: Influence of Treatment on the Fibers Properties}

\begin{abstract}
The aim of this work is to evaluate the influence of the sugar cane bagasse $\mathrm{NaOH}$ treatment in the mechanical and dynamic-mechanical properties, in the thermal stability, density and water absorption, when used in unsaturated polyester resin/sugar cane bagasse composite. The sugar cane bagasse was submitted to the chemical treatment with alkaline solution of $\mathrm{NaOH}$. The treatment improves the impact and flexural elasticity modulus when compared with resin without fibers, in addition to the adhesion of the fibers with the matrices, but does not improve significantly the tensile elasticity modulus. The surfaces of the impact fracture were analyzed by SEM.
\end{abstract}

Keywords: Unsaturated polyester resin, sugar cane bagasse, mercerization, mechanical properties, dynamic mechanical properties, fiber-matrix adhesion.

\section{Introdução}

Atualmente muitas pesquisas têm avaliado a viabilidade da utilização de fibras naturais como uma alternativa para as fibras sintéticas convencionalmente utilizadas como reforço em materiais compósitos de matriz polimérica. Este interesse se deve à necessidade de se encontrar fontes renováveis de matéria-prima, de reduzir o impacto ambiental dos materiais e reduzir custos ${ }^{[1-10]}$.

Fibras celulósicas como bagaço de cana-de-açúcar, sisal, banana, coco, madeira e juta, têm sido incorporadas em vários termoplásticos e termofixos como reforço ou carga ${ }^{[11]}$.

As resinas termofixas são muito empregadas devido às diversas vantagens como: baixo custo, estabilidade térmica e dimensional, resistência química a altas temperaturas e facilidade de se moldar peças com grandes dimensões; no entanto a sua baixa resistência à fratura torna necessária a utilização de reforços.

Joshi et al. avaliaram o ciclo de vida de compósitos com diferentes fibras naturais em relação a um compósito com fibras de vidro e chegaram a conclusão que em relação aos aspectos ambientais, os compósitos com fibras naturais são ambientalmente superiores. Estes apresentam menor impacto durante a produção, menor peso quando utilizados em veículos de transporte aumentando a eficiência energética. $\mathrm{O}$ fato de se necessitar uma maior quantidade de fibras naturais para se obter o mesmo desempenho que as fibras de vidro pode ser relacionado à redução da poluição associada à quantidade de polímero. No final do ciclo de vida o material pode ser incinerado fornecendo energia e créditos de carbono ${ }^{[12]}$.

O Brasil é um grande produtor de bagaço de cana-de-açúcar. O bagaço de cana é o principal exemplo de subproduto da agroindústria brasileira, que pode ser reaproveitado como adubo ou fonte de energia (como combustível), com baixo custo.

O bagaço, um resíduo lignocelulósico fibroso obtido da última moagem da cana, é formado por um conjunto de partículas heterogêneo (grãos e fibras) com tamanhos variando de 1 a $25 \mathrm{~mm}$, mas com um tamanho médio de aproximadamente $2 \mathrm{~mm}$. O tamanho das partículas do bagaço depende principalmente do tipo de equipamento utilizado no processamento da cana e, de uma maneira menos significativa, da variedade da cana. As fibras do bagaço de cana-de-açúcar são formadas por polímeros naturais, principalmente a lignina, a hemicelulose e a celulose $\mathrm{e}^{[13]}$.

A celulose é o principal componente estrutural das fibras vegetais. Os componentes lignina e hemicelulose também têm uma importante participação nas propriedades características das fibras. A hemicelulose é um polissacarídeo complexo, de baixa massa molar que inclui carboidratos poliméricos com cinco a seis átomos de carbono na estrutura das suas unidades de açúcar. A complexidade estrutural das hemiceluloses é responsável por propriedades como a ausência de cristalinidade, baixa massa molar e alta absorção de água. A hemicelulose é muito sensível à ação da soda caústica, que afeta apenas ligeiramente a lignina e a $\alpha$-celulose. A lignina é constituída por macromoléculas tridimensionais de fenilpropano. Por apresentar estrutura complexa e de alta massa molar a lignina apresenta-se predominantemente amorfa. As plantas de modo geral apresentam um teor de lignina entre 26 a 34\%. A lignina confere rigidez à parede celular e na madeira age como ligação entre as células, gerando uma estrutura resistente ao impacto, à compressão e à dobra. As madeiras são classificadas de acordo com o teor de lignina. Madeiras são consideradas duras quando o teor de lignina está entre 16 a $24 \%$ e essa classificação irá determinar a aplicação $^{[14]}$. 
Comparadas com outras fibras, as de bagaço de cana-de-açúcar apresentam menor resistência a tração, menor módulo de elasticidade, maior umidade e melhor degradabilidade, devido ao seu alto teor de hemicelulose $(27 \%)$ e lignina $(21 \%)^{[11]}$, enquanto as fibras de juta e sisal apresentam 13 e $13 \%, 13$ e $11 \%$, respectivamente ${ }^{[15]}$.

A grande dificuldade na fabricação de compósitos de materiais poliméricos com fibras naturais está na adesão entre a fibra e a matriz, além da absorção de água pela fibra e sua baixa resistência a ataques químicos e microbiológicos ${ }^{[7]}$.

A estrutura e a natureza da interface fibra matriz desempenham um papel importante nas propriedades mecânicas e físicas dos materiais compósitos porque é através desta interface que ocorre a transferência da carga da matriz para a fibra ${ }^{[16]}$.

Para melhorar a adesão na interface fibra/matriz, as fibras naturais precisam ser submetidas a tratamentos químicos, para que possam interagir com a matriz polimérica ${ }^{[1]}$.

O tratamento alcalino (mercerização) das fibras é uma das possibilidades de baixo custo $^{[16]}$. Os efeitos da mercerização como um tratamento para melhorar as propriedades mecânicas, especialmente a resistência à tração de fibras de algodão, tem sido extensivamente estudados. A definição de mercerização proposta pela ASTM D1695 considera este um processo no qual fibras vegetais são submetidas a uma interação com solução aquosa de uma base forte, para produzir grande intumescimento, resultando em mudanças na estrutura, nas dimensões, na morfologia e nas propriedades mecânicas das fibras ${ }^{[15]}$.

$\mathrm{O}$ intumescimento leva a um distanciamento das cadeias celulósicas, quebrando as ligações de hidrogênio. A presença de hidroxilas, provenientes do tratamento com bases fortes contribui também para a quebra destas ligações, formando ligações de hidrogênio com as cadeias celulósicas. Esse processo de quebra/ interação de ligações disponibiliza grupos que antes eram inacessíveis a agentes químicos, para efetuarem ligações de hidrogênio intra e intermoleculares. Após o tratamento alcalino as fibras apresentam maior superfície de contato, possibilitando uma maior interação com outros materiais ${ }^{[14,15]}$.

Estudos sobre o tratamento alcalino em fibras de juta, por exemplo, mostraram que a remoção de lignina e hemicelulose afetaram as características de tração das fibras. Quando as hemiceluloses são removidas a região interfibrilar provavelmente se torna menos densa e menos rígida permitindo que as fibrilas se tornem mais capazes de se rearranjarem na direção da deformação. Quando fibras naturais são estiradas, esses rearranjos entre as fibrilas podem resultar em uma melhor distribuição de carga, resultando no desenvolvimento de maior tensão por parte da fibra. Em contraste o amolecimento da região interfibrilar na matriz afeta adversamente a transferência de tensão entre as fibrilas e, portanto, o desenvolvimento global da tensão da fibra submetida à tração. Como a lignina é removida gradualmente, o centro da lamela de junção das células pode se tornar mais plástica e bem mais homogênea devido à eliminação gradual de micro-vazios, enquanto as células principais são afetadas apenas ligeiramente ${ }^{[15]}$.

Para viabilizar o emprego de materiais compósitos, principalmente quando se utiliza fibras pouco avaliadas, garantindo sua competição com materiais convencionalmente empregados, seja por critérios de custo ou requisitos de projeto, é de vital importância que se conheça suas propriedades químicas e mecânicas.

Neste trabalho foram avaliadas as propriedades dinâmico-mecânicas, mecânicas de tração, flexão e impacto de compósitos confeccionados com fibras de bagaço de cana-de-açúcar tratadas e não tratadas com solução de hidróxido de sódio. As propriedades foram comparadas com as da resina sem reforço. Foi avaliada a estabilidade térmica por análise termogravimétrica dos materiais compósitos, dos bagaços tratados e não tratados, e da resina sem reforço. A verificação da adesão das fibras à matriz foi baseada na microscopia eletrônica de varredura das fraturas obtidas nos ensaios de resistência ao impacto. A modificação da estrutura química da superfície das fibras foi avaliada por espectroscopia na região de infravermelho. Avaliou-se também a densidade dos compósitos obtidos e a sua capacidade de absorção de umidade.

\section{Experimental}

\section{Materiais}

Foi utilizada uma resina de poliéster insaturado comercial, ortoftálica (ARAZIN 4.1), contendo aproximadamente $38 \%$ em massa de estireno, pré-acelerada com octoato de cobalto. Utilizou-se o peróxido metil-etil-cetona, MEKP, como iniciador de cura, bagaço de cana-de-açúcar (Usina Açucareira Ester, Cosmópolis, SP), solução de hidróxido de sódio 10\% em massa e ácido clorídrico.

\section{Tratamento do bagaço}

O bagaço de cana-de-açúcar passou por um processo de separação granulométrica $(0,5<\phi<0,7 \mathrm{~mm})$ e posteriormente foi seco em estufa a $100{ }^{\circ} \mathrm{C}$ por 5 horas.

O tratamento com solução de hidróxido de sódio $10 \%$ em massa foi feito imergindo as fibras por 24 horas à temperatura ambiente nesta solução ( 1 fibra/5 solução, m/m). Após este intervalo de tempo, as fibras foram retiradas da solução e lavadas por diversas vezes até $\mathrm{pH}$ neutro. As fibras foram secas por 5 horas a $100{ }^{\circ} \mathrm{C}$.

\section{Preparação do compósito}

As fibras foram misturadas manualmente com a resina antes da cura, na proporção de $15 \%$ em massa (maior quantidade possível de ser obtida por mistura manual). As misturas foram curadas utilizando-se $0,5 \%$ em massa de solução de peróxido metil-etil-cetona como iniciador. Foram utilizados moldes de teflon (macho e fêmea) com dimensões de $130 \times 130 \times 3 \mathrm{~mm}$, sob a carga de $1 \mathrm{t}$ por 24 horas, à temperatura ambiente. As placas obtidas foram retiradas do molde e submetidas a pós cura a $60^{\circ} \mathrm{C}$ por 48 horas em uma estufa com circulação de ar.

Foram cortados corpos de prova para ensaios de resistência ao impacto (ASTM D256), para ensaios de flexão (ASTM D790), tração (ASTM D638) e análise dinâmico-mecânica das placas.

\section{Caracterização}

Os ensaios mecânicos de tração foram realizados segundo a norma ASTM D638. A velocidade do ensaio foi de $50 \mathrm{~mm} / \mathrm{s}$, a distância inicial entre garras foi de $70 \mathrm{~mm}$, à temperatura ambiente, na máquina universal de ensaios Tinius Olsen, modelo H5K-S.

Os ensaios de flexão em três pontos foram conduzidos segundo a norma ASTM D790, na velocidade de $50 \mathrm{~mm} / \mathrm{s}$, com $90 \mathrm{~mm}$ entre os pontos de apoio, à temperatura ambiente, na máquina universal de ensaios Tinius Olsen, modelo H5K-S.

Os ensaios de impacto foram conduzidos segundo a norma ASTM D256, em amostras entalhadas, método Izod, com martelo de 2,7 J, à temperatura ambiente na máquina Tinius Olsen 892.

A análise dinâmico mecânica (DMA) foi realizada com amostras de aproximadamente $25 \times 10 \times 3 \mathrm{~mm}$ na faixa de temperatura de 25 a $200{ }^{\circ} \mathrm{C}$. A taxa de aquecimento foi de $5{ }^{\circ} \mathrm{C} / \mathrm{min}$, a amplitude de $0,2 \mathrm{~mm}$ e a frequência de $1 \mathrm{~Hz}$. O equipamento utilizado foi o DMA 242 Netzsch.

A análise termogravimétrica (TGA) foi realizada com amostras de corpos de prova e de fibras de bagaço de cana tratadas e não 
tratadas. As amostras foram aquecidas na taxa de $10^{\circ} \mathrm{C} / \mathrm{min}$, desde a temperatura ambiente até $800^{\circ} \mathrm{C}$, no equipamento Netzsch TG 209, utilizando nitrogênio gasoso.

As fraturas obtidas nos ensaios de resistência ao impacto e as fibras antes e após o tratamento foram analisadas no microscópio eletrônico de varredura JEOL JXA-840A, após recobrimento com ouro. As fibras foram analisadas com aumentos de 500 e $1000 \times$ e as fraturas com aumentos variando entre 15, 200 e $500 \times$.

Os espectros na região de infravermelho das fibras foram obtidos no espectrofotômetro Nicolet Protege 460 a partir de pastilhas de brometo de potássio e fibras de bagaço de cana-de-açúcar.

Para o cálculo da densidade mediu-se a massa e o volume por deslocamento de água em um picnômetro, de três pedaços do material. Os cálculos foram obtidos em $\mathrm{g} / \mathrm{cm}^{3}$.

Para a avaliação da absorção de água (ASTM D570) mediu-se a massa de um pedaço do material; este foi submerso em água por um período de 72 horas e fez-se nova medida da massa do material seco com papel toalha após este período.

\section{Resultados e Discussão}

\section{Caracterização das fibras de bagaço de cana}

Na Figura 1 são mostradas as curvas de TGA obtidas com amostras das fibras de bagaço.

Nota-se que as fibras tratadas com hidróxido de sódio apresentaram significativo aumento na estabilidade térmica e na temperatura de início de perda de massa. O processo de mercerização, ao qual as fibras foram submetidas, resultou na perda dos compostos solúveis do bagaço (hemicelulose e parte da lignina).

As fibras naturais apresentam degradação em duas etapas principais. A primeira corresponde à despolimerização térmica da hemicelulose e a quebra de ligações glicosídicas da celulose. A segunda está relacionada com a decomposição da $\alpha$-celulose. A decomposição da lignina acontece numa ampla faixa de temperatura, entre 200 e $500{ }^{\circ} \mathrm{C}^{[2]}$.

A Figura 2 mostra os espectros de infravermelho das fibras não tratadas e das fibras tratadas com solução de hidróxido de sódio $10 \%$. Através da análise foi possível determinar os principais grupos funcionais presentes no espectro. Grupos carbonila livre ocorrem abundantemente dentro de polímeros que compõem a madeira, no entanto são mais proeminentes em cadeias ramificadas de hemicelulose. Segundo Barker e Owen ${ }^{[17]}$ espectros isolados de lignina e holocelulose (celulose + hemicelulose) confirmam que há absorção de grupos carbonila mais proeminentemente no último componente. Rong et al. ${ }^{[18]}$ sugerem a perda de massa de fibras de sisal tratadas com $\mathrm{NaOH}$ em função da dissolução de hemicelulose durante o tratamento alcalino.

Identificou-se a absorção associada a grupos O-H $\left(3350 \mathrm{~cm}^{-1}\right) \mathrm{e}$ grupos C-H $\left(2880 \mathrm{~cm}^{-1}\right)$ nas fibras tratadas e nas fibras não tratadas. A absorção em $3350 \mathrm{~cm}^{-1}$ ficou mais definida nas fibras submetidas ao tratamento alcalino, o que indica o aumento de grupos $\mathrm{O}-\mathrm{H}$. Paul et al. ${ }^{[19]}$ descrevem o aumento da absorção associada a grupos hidroxila em função da quebra de ligações de lignina e hemicelulose com celulose após o tratamento alcalino, o que resulta no aumento de grupos O-H. A modificação da superfície da fibra ficou evidente no tratamento com hidróxido de sódio. Devido à mercerização, componentes solúveis das fibras são retirados, é o caso da hemicelulose e pequena parte de lignina que compõem as fibras. Portanto, observa-se, que a absorção associada aos grupos carbonila $\mathrm{C}=\mathrm{O}\left(1650 \mathrm{~cm}^{-1}\right)$ desaparece nas fibras tratadas com $\mathrm{NaOH}$.
As Figuras 3 e 4 mostram as micrografias das fibras tratadas com solução de hidróxido de sódio em comparação com as não tratadas. $\mathrm{Na}$ Figura 3 tem-se um aspecto geral das fibras, onde se verifica que, após o tratamento estas se tornaram mais finas e emanharadas. Na Figura 4 observa-se que o tratamento produz uma remoção de partículas na superfície das fibras, enquanto que nas fibras sem tratamento estas se apresentam "soltas" na superfície.

\section{Caracterização dos compósitos}

Na Figura 5 são mostradas as curvas de análise termogravimétrica para os compósitos e para a resina. Observa-se que para os compósitos a estabilidade térmica não é significativamente alterada pela adição de bagaço e nem pelo tratamento deste. O processo de degradação ocorre em duas etapas, sendo o primeiro o de maior importância, no qual ocorre a perda, em média, de $91 \%$ de massa. A quantidade de resíduos dos compósitos é ligeiramente superior ao da resina. A Tabela 1 mostra as temperaturas iniciais de perda de massa (Tipm) da resina não reforçada e dos compósitos.

Na Tabela 2 são mostrados os resultados dos ensaios mecânicos, de densidade e absorção de água.

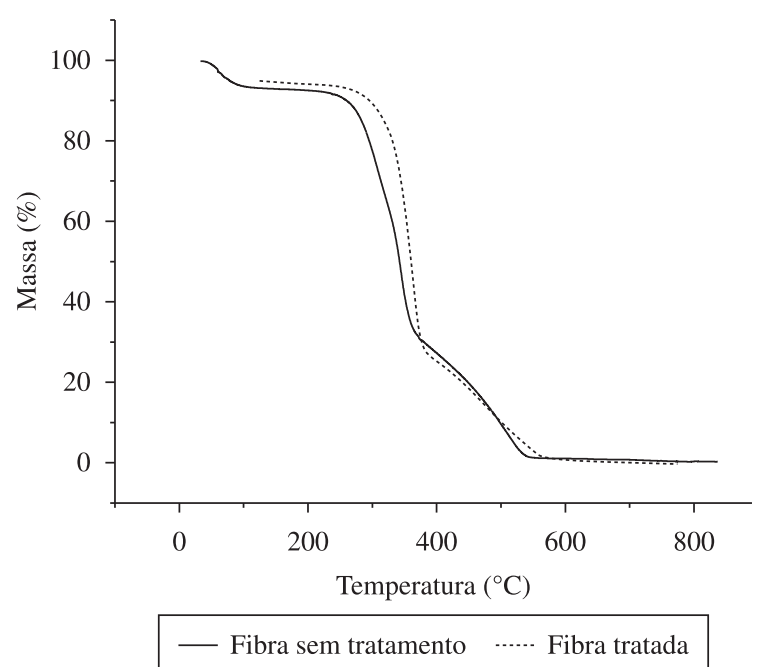

Figura 1. Curvas termogravimétricas das fibras de bagaço.

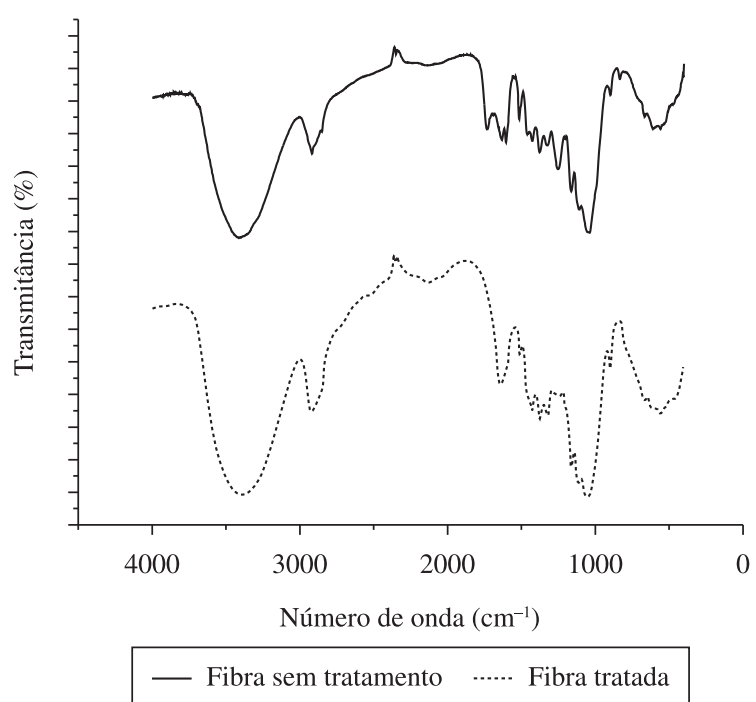

Figura 2. Espectro de infravermelho das fibras tratadas e não tratadas. 

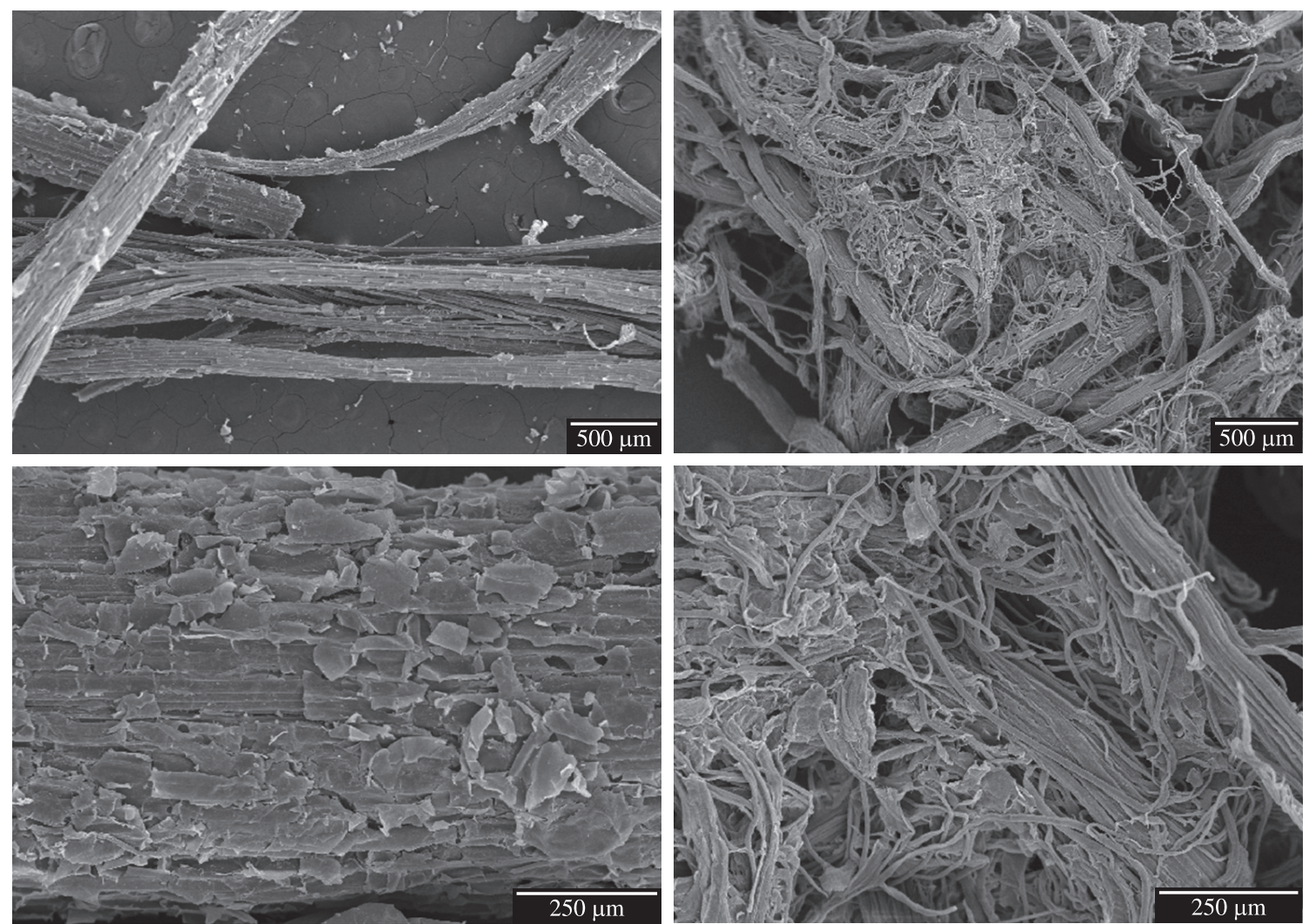

Fibra sem tratamento

Fibra tratada com $\mathrm{NaOH} 10 \%$

Figura 3. Microscopia eletrônica de varredura das fibras de bagaço com e sem tratamento (aumentos de 30 e 100x).
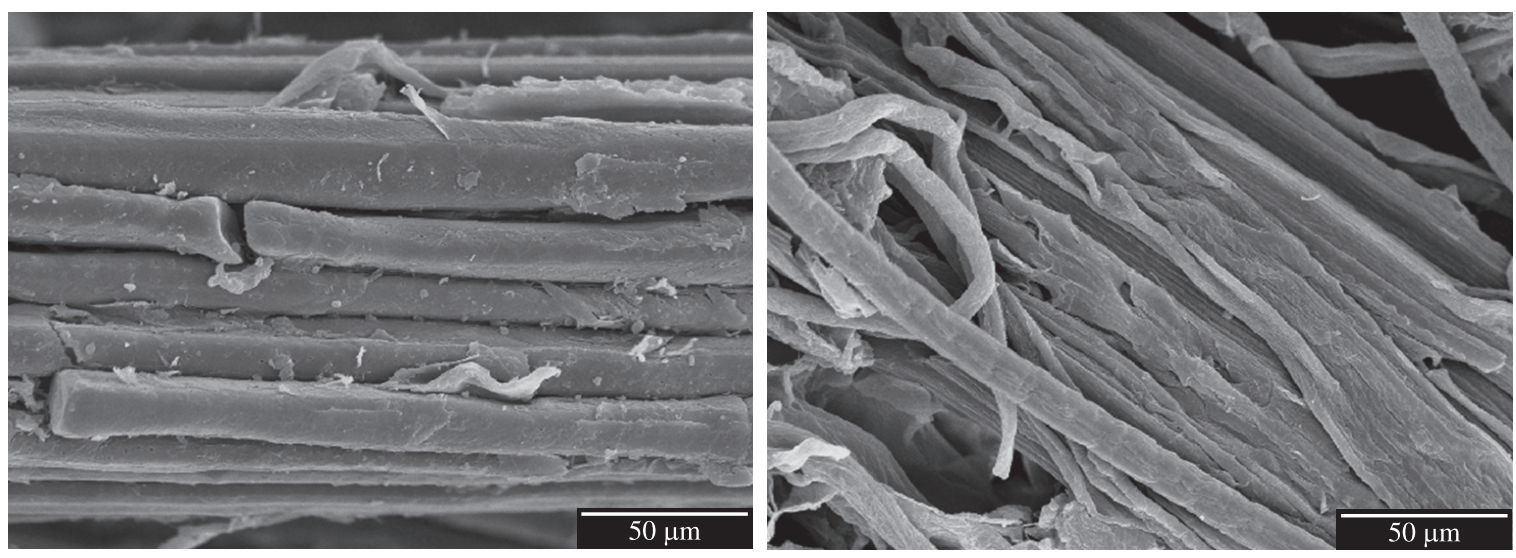

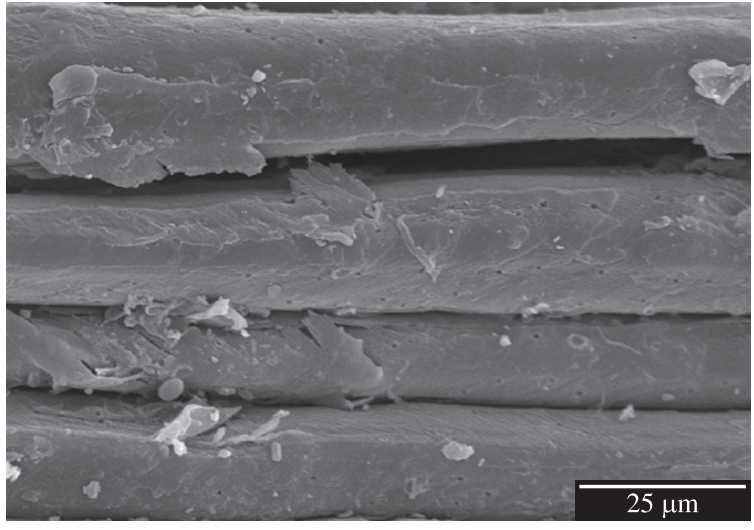

Fibra sem tratamento

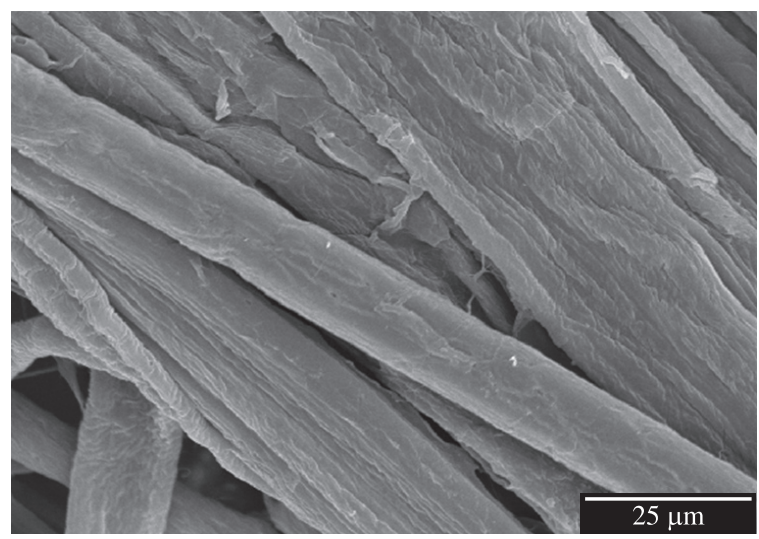

Fibra tratada com $\mathrm{NaOH} 10 \%$

Figura 4. Microscopia eletrônica de varredura das fibras de bagaço com e sem tratamento (aumentos de 500 e 1000x). 
Os resultados obtidos nos ensaios de resistência ao impacto dos compósitos e da resina sem reforço revelam que em todos os compósitos confeccionados com fibras, a resistência ao impacto foi superior, se comparada com a resina ${ }^{[20]}$.

Nos resultados dos ensaios de tração observa-se que a adição das fibras de bagaço à resina origina compósitos com valores de alongamento na ruptura inferiores, se comparados com as resinas. $\mathrm{O}$ aumento da adesão ou área interfacial das fibras lignocelulósicas por mercerização não é o único fator que afeta a ancoragem mecânica da matriz com o reforço. Fibras com maior rigidez que a matriz podem aumentar o módulo de elasticidade, mas geralmente diminuem o alongamento. Se a adesão é pobre o alongamento deve diminuir mais intensamente. Segundo Marcovich et al. a diminuição no alongamento em relação à resina sem reforço sugere bom nível de compatibilidade interfacial entre a resina e as partículas de madeira, independente do tratamento ${ }^{[1]}$.

A resistência à tração diminuiu com a adição das fibras à resina. Porém, os compósitos confeccionados com fibras tratadas com hidróxido de sódio mostraram significativo aumento nos valores da propriedade, em relação aos compósitos com fibra não tratada.

O módulo de elasticidade em tração diminuiu nos compósitos com bagaço não tratado e não variou significativamente para os compósitos com bagaço tratado, em relação à resina sem reforço.

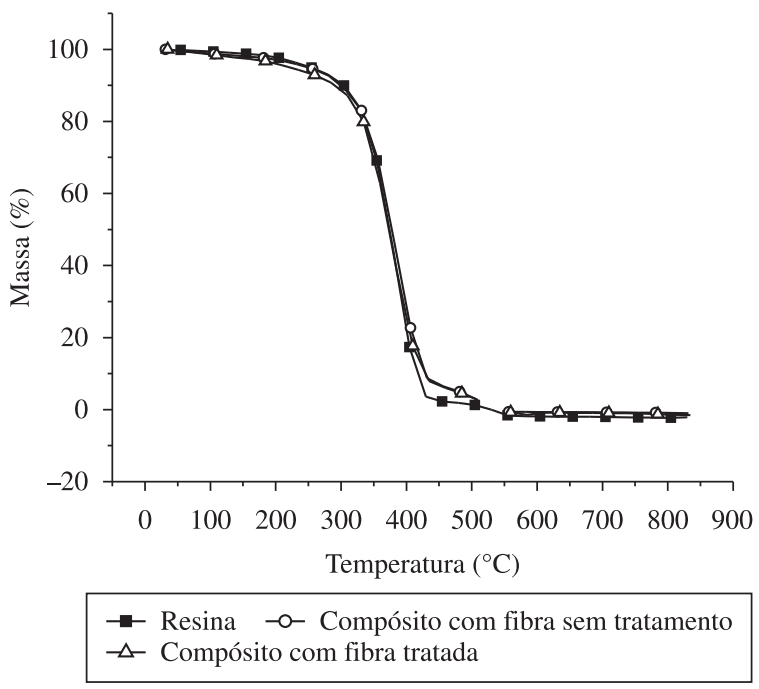

Figura 5. Curvas termogravimétricas da resina e do compósito com fibras de bagaço sem tratamento e com fibras de bagaço tratado com NaOH $10 \%$.

Tabela 1. Temperatura inicial de perda de massa das placas (Tipm).

\begin{tabular}{lc}
\hline \multicolumn{1}{c}{ Placa } & Tipm $\left({ }^{\circ} \mathbf{C}\right)$ \\
\hline Resina & 339 \\
Compósito com fibras de bagaço sem tratamento & 344 \\
Compósito com fibras de bagaço tratadas com $\mathrm{NaOH} 10 \%$ & 334 \\
\hline
\end{tabular}

Em flexão verifica-se maior módulo de elasticidade com a adição de fibras, principalmente as tratadas com hidróxido de sódio, se comparados com a resina sem reforço.

A densidade dos materiais revela que a adição de fibras à resina torna o material compósito final menos denso. A baixa densidade é uma característica importante dos compósitos poliméricos reforçados com fibras naturais quando comparados aos compósitos reforçados com fibras sintéticas. No compósito com bagaço tratado a melhor adesão fibra-matriz provavelmente diminuiu os vazios no material em relação ao compósito com bagaço não tratado. Em compósitos com pó de madeira tratado e não tratado com $\mathrm{NaOH}$, a densidade do compósito não foi afetada em relação a da matriz de poliéster ${ }^{[1]}$.

A resistência à água em polímeros é avaliada pela absorção de umidade, que aumenta as dimensões da peça prejudicando a aplicação em trabalhos de precisão. A absorção de água é mais fácil quando a molécula do polímero apresenta grupamentos capazes de formar pontes de hidrogênio. Por exemplo, peças de náilon, madeira ou celulose podem absorver umidade, mudando de dimensões. A absorção de água pode aumentar muito o peso do material polimérico $^{[4]}$.

A absorção de água pela resina é praticamente nula, já que esta tem caráter hidrofóbico. A adição de fibras naturais à resina gera um aumento na absorção de água. Nota-se que os compósitos com fibras não tratadas absorvem mais água do que os compósitos com fibras tratadas. Isto se deve ao fato de que o tratamento químico das fibras naturais aumenta a interação na interface fibra/matriz, diminuindo os espaços vazios nesta interface e, consequentemente a

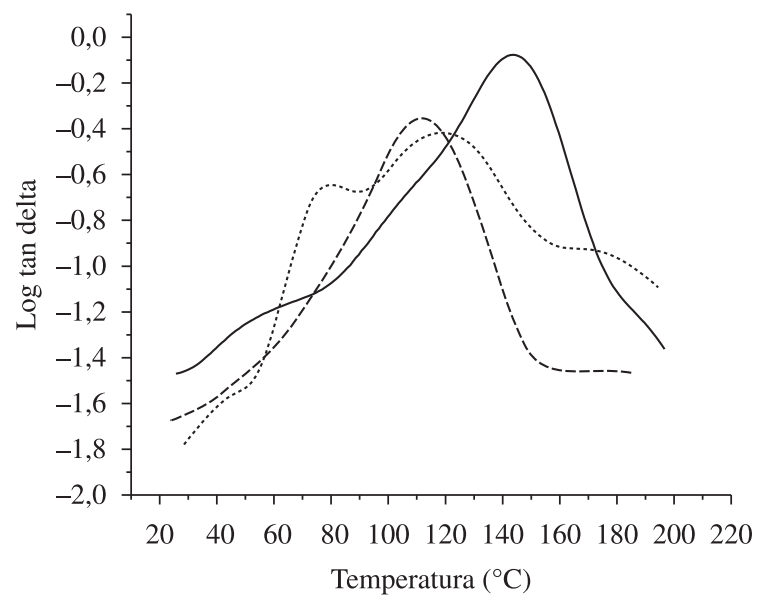
- Resina ….. Compósito com fibras sem tratamento
--- Compósito com fibras tratadas

Figura 6. Curvas de $\tan \delta$ da resina, do compósito com fibras de bagaço sem tratamento e do compósito com fibras de bagaço tratadas com NaOH $10 \%$.

Tabela 2. Propriedades físicas e mecânicas da resina sem reforço e dos compósitos

\begin{tabular}{lccc}
\hline \multicolumn{1}{c}{ Propriedade } & Resina & $\begin{array}{c}\text { Compósitos com fibras de } \\
\text { bagaço sem tratamento }\end{array}$ & $\begin{array}{c}\text { Compósitos de fibras de bagaço } \\
\text { tratadas com NaOH 10\% }\end{array}$ \\
\hline Resitência ao impacto $\left(\mathrm{J}^{-\mathrm{m}^{-1}}\right)$ & $10,8 \pm 1,5$ & $16,1 \pm 1,4$ & $25,2 \pm 2,1$ \\
Resitência ao impacto $\left(\mathrm{J} . \mathrm{m}^{-2}\right)$ & $1025 \pm 131$ & $1820 \pm 337$ & $2558 \pm 207$ \\
Alongamento na ruptura (\%) & $5,5 \pm 0,9$ & $2,8 \pm 0,3$ & $3,7 \pm 0,4$ \\
Tensão máxima (MPa) & $42,3 \pm 6,7$ & $15,4 \pm 0,8$ & $27,7 \pm 0,5$ \\
Módulo de elasticidade em tração (MPa) & $844 \pm 105$ & $702 \pm 34$ & $856 \pm 70$ \\
Módulo de elasticidade em flexão (MPa) & $3300 \pm 106$ & $3400 \pm 311$ & $4041 \pm 218$ \\
Densidade (g.m ${ }^{-3}$ ) & $1,17 \pm 0,02$ & $0,92 \pm 0,07$ & $1,27 \pm 0,08$ \\
Absorção de água em 72 horas (\%) & $0,4635 \pm 0,0001$ & $10,5719 \pm 0,0001$ & $3,3512 \pm 0,0001$ \\
\hline
\end{tabular}


absorção de água. Deve-se ressaltar que a taxa de absorção de água foi calculada para as primeiras 72 horas em que o material ficou submerso em água. É provável que após um período maior de tempo ocorra saturação das fibras.

$\mathrm{O}$ efeito do tratamento químico das fibras nas propriedades dinâmico-mecânicas também foi estudado. As curvas do fator de perda, $\tan \delta$, em função da temperatura, obtidas por análise dinâmico-mecânica das placas são mostradas na Figura 6 . Movimentos significativos em níveis moleculares, como é o caso da transição vítrea $\left(\mathrm{T}_{\mathrm{g}}\right)$, foram identificados. As resinas de poliéster insaturado se tornam insolúveis e rígidas pela reticulação com o monômero estireno, presente na faixa de 30 a $40 \%$ em massa nas resinas comerciais. As resinas de poliéster são bastante dependentes da quantidade de estireno e portanto, a segregação de fases entre o estireno, a resina e outros componentes afeta a cinética de cura. ${ }^{[1]}$ Um pico acentuado em torno de $150^{\circ} \mathrm{C}$ é observado para a resina. $\mathrm{O}$ compósito de resina com bagaço não tratado mostra características de um material com duas fases e a transição vítrea principal a uma temperatura abaixo da resina. Como as fibras não tratadas podem absorver mais resina que as tratadas, a cura pode ter ocorrido em diferentes extensões, levando à observação de duas transições. Já para o compósito de resina com fibras tratadas com hidróxido de sódio houve o deslocamento da $\mathrm{T}_{\mathrm{g}}$ para uma faixa de temperatura intermediária entre a do compósito com fibra não tratada e a da resina, podendo ser um indício de melhora na compatibilidade entre o reforço e a matriz, pois se observa uma única transição.

As Figuras de 7-9 mostram as análises das superfícies fraturadas das amostras de compósitos com aumento de 15 e 500×. Na Figura 7
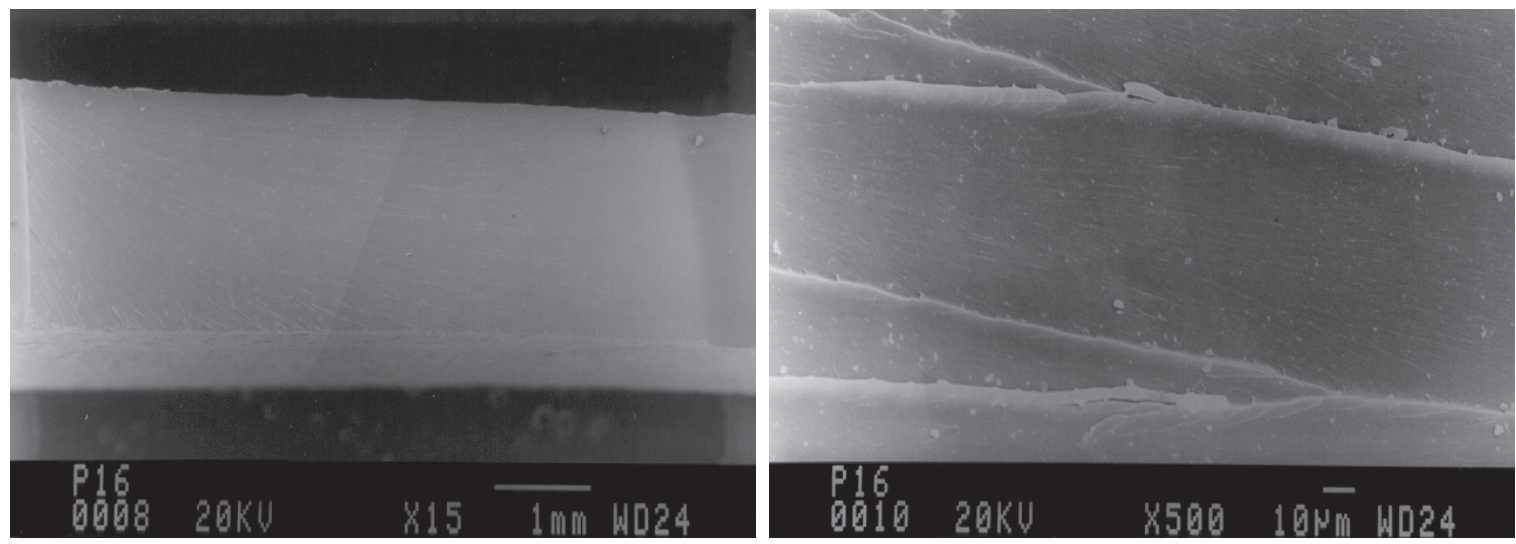

Figura 7. Microscopia eletrônica de varredura da fratura obtida no ensaio de impacto para a resina.
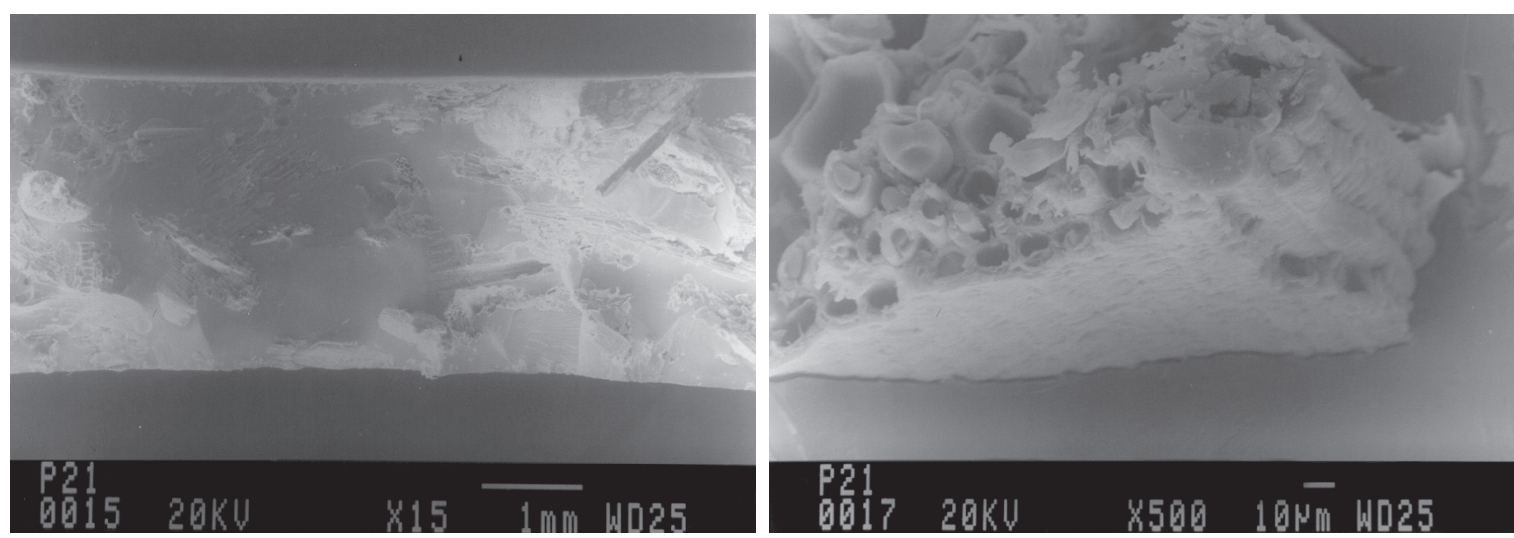

Figura 8. Microscopia eletrônica de varredura da fratura obtida no ensaio de impacto para o compósito com bagaço sem tratamento.
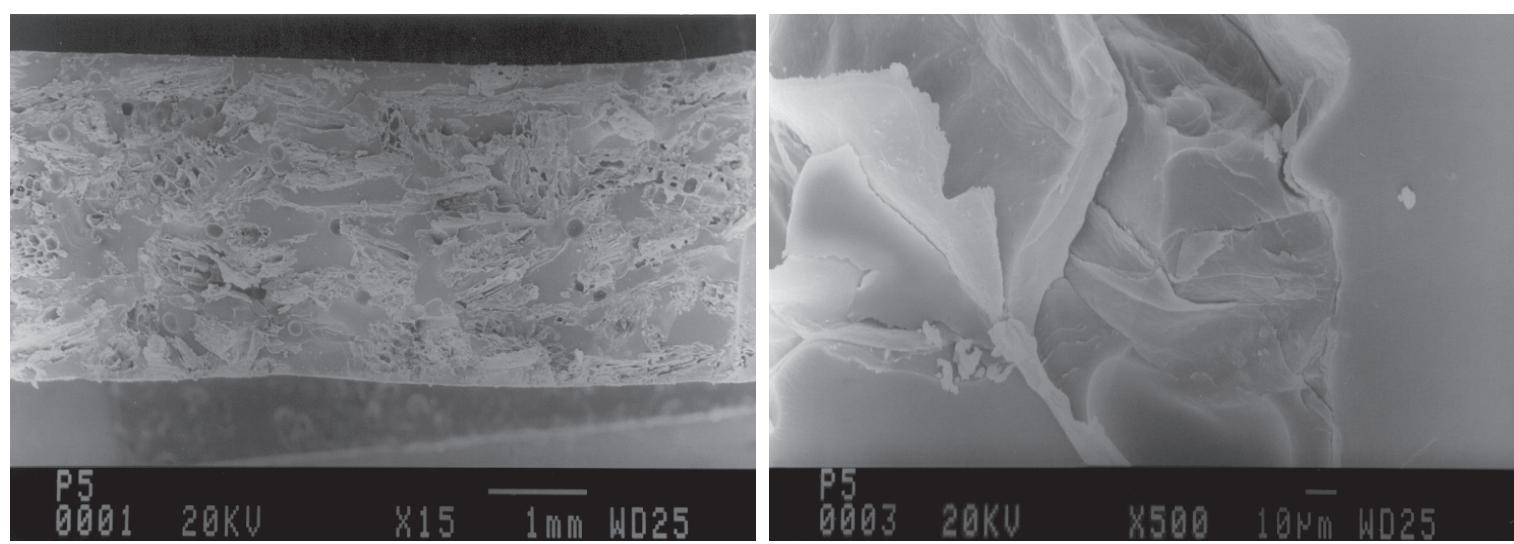

Figura 9. Microscopia eletrônica de varredura da fratura obtida no ensaio de impacto para o compósito com bagaço tratado com $\mathrm{NaOH} 10 \%$. 


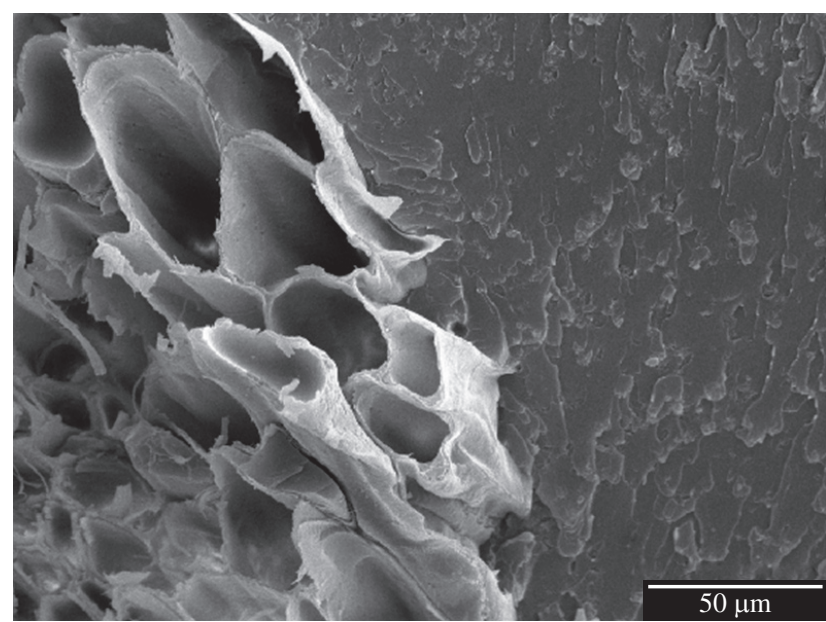

Compósito com fibra sem tratamento

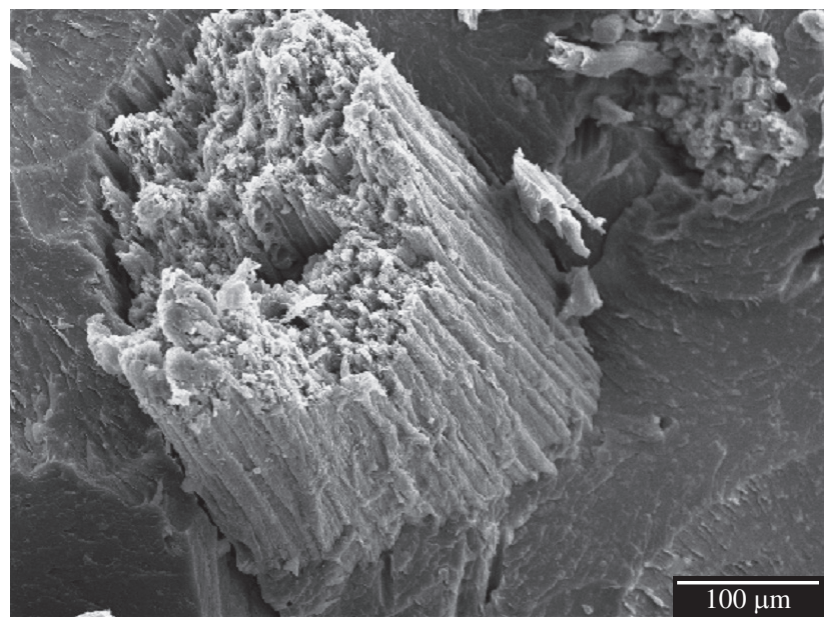

Compósito com fibra tratada com $\mathrm{NaOH} 10 \%$

Figura 10. Microscopia eletrônica de varredura da fratura obtida no ensaio de impacto para o compósito com fibra de bagaço sem tratamento e para o compósito com fibra de bagaço tratada com $\mathrm{NaOH} 10 \%$ (aumentos de 500 e 200x, respectivamente).

observa-se uma fratura típica de resina termofixa. Comparando-se com as fraturas dos compósitos pode-se observar que as fibras tratadas (Figura 9) estão mais dispersas na matriz que as não tratadas (Figura 8). As placas feitas com fibras sem tratamento apresentaram falhas na adesão fibra/matriz, já os compósitos feitos com fibras tratadas mostram boa adesão da fibra com a matriz polimérica, confirmando que a alteração química da superfície da fibra melhorou a adesão. Na Figura 10 pode-se observar que a fibra de bagaço tratada foi parcialmente preenchida pela resina. A matriz penetrou nos capilares das fibras, mas também foram encontrados capilares vazios.

\section{Conclusão}

$\mathrm{O}$ tratamento das fibras de bagaço de cana com $\mathrm{NaOH}$ melhorou as propriedades de impacto; aumentou o módulo de elasticidade em flexão, resultado importante pois é um tipo de solicitação mecânica característico para chapas de materiais laminados; não alterou significativamente o módulo de elasticidade em tração dos compósitos em relação à resina sem reforço e melhorou a compatibilidade fibra matriz quando comparada com compósitos com a fibra sem tratamento. Nota-se a modificação química da superfície das fibras tratadas no espectro de infravermelho e a melhor aderência fibra/matriz nas fraturas de impacto avaliadas por microscopia eletrônica de varredura. A análise termogravimétrica mostra o aumento da estabilidade térmica dos bagaços tratados. A análise dinâmico-mecânica mostra que a adição de fibras de bagaço altera a temperatura de transição vítrea dos compósitos e que para as fibras tratadas a boa incorporação é evidenciada pela transição única, porém a uma temperatura menor que da resina.

\section{Referências Bibliográficas}

1. Marcovich, N. E.; Aranguren, M. I. \& Reboredo, M. M. - Polymer, 42, p.815 (2001)

2. Manfredi, L. B.; Rodríguez, E. S.; Wladyka-Przybylak, M. \& Vázquez, A. - Polymer Degradation and Stability, 91, p.255 (2006).

3. Idicula, M.; Boudenne, A.; Umadevi, L.; Ibos, L.; Candau, Y. \& Thomas S. - Composites Science and Technology, 66, p.2719 (2006).

4. Athijayamani, A.; Thiruchitrambalam, M.; Natarajan, U. \& Pazhanivel, B. - Materials Science and Engineering A, 517, p.344 (2009).
5. Silva, F. de A.; Chawla, N. \& Toledo Filho, R. D. de - Composites Science and Technology, 68, p.3438 (2008).

6. Joseph, K.; Medeiros, E. S. \& Carvalho, L. H. - Polímeros, Out/Dez, p.136 (1999).

7. Carvalho, L. H.\& Cavalcanti, W. S. - Polímeros, 16, p.33 (2006).

8. Paiva, J. M. F. \& Frollini, E. - Journal of Applied Polymer Science, 83, p.880 (2002).

9. Tita, S. P. S.; Paiva, J. M. F. \& Frollini E. - Polímeros, 12, p.228 (2002).

10. Hoareau, W.; Trindade, W. G.; Siegmund, B.; Castellana, A. \& Frollini, E. - Polymer Degradation and Stability, 86, p.567 (2004).

11. Bertoti, A. R.; Luporini, S. \& Esperidião, M. C. A. - Carbohydrate Polymers, 77, p.20 (2009).

12. Joshi, S. V.; Drzal, L. T.; Mohanty, A. K. \& Arora, S. - Composites: Part A, 35, p.371 (2004).

13. Estevez, A. G.; Gálvez, L. \& De La Osa, O. - "Sugar Cane Bagasse. Utilization for Prodution of Composites. The State of the Art in Cuba", in: Lignocellulosic - Plastics Composites, Leão, A. L.; Carvalho, F. X. \& Frollini, E. (ed.), UNESP, São Paulo, Brasil (1997).

14. Carvalho, L. F. M. - "Fibras de Palha de Carnaúba: Caracterização Térmica e Aplicações em Compósitos", Dissertação de Mestrado, Universidade Federal do Piauí, Brasil, (2004).

15. Bledzki, A. K. \& Gassan, J. - Prog. Polym. Sci., 24, p.221 (1999).

16. Razera, I. A. T. \& Frollini, E. - Journal of Applied Polymer Science, 91 , p.1077 (2004).

17. Barker, B. \& Owen, N. L., J. Chem. Ed., 76, p.1706 (1999).

18. Rong, M. Z.; Zhang, M. Q.; Liu, Y., Yang, G. C. \& Zeng, H. M.; Composites Science and Technology, 61, p.1437 (2001).

19. Paul, A.; Joseph, K. \& Thomas, S., Composites Science and Technology, 57, p.67 (1997).

20. Cavani, C. S.; Sanchez, E. M. S.; Leal, C. V. \& Sánchez, C. G. "Compósito de Resina de Poliéster com Bagaço de Cana: Influência de Tratamento das Fibras na Resistência ao Impacto" - in: Anais do $7^{\circ}$ Congresso Brasileiro de Polímeros, Belo Horizonte, MG (2003).

21. Sanchez, E. M. S.; Zavaglia, C. A. C. \& Felisberti, M. I. - Polymer, 41, p.765 (2000).

Enviado: $16 / 10 / 09$

Reenviado: 08/02/10

Aceito: $22 / 02 / 10$

DOI: $10.1590 /$ S0104-14282010005000034 